Artykuly / Articles

Виктория Борецкая

ORCID: 0000-0002-8299-6213

boreckawk@mail.ru

Ваментина Яхно

ORCID: 0000-0002-3743-6479

vny56@mail.ru

Гомельский государственный технический университет им. П.О. Сухого

Гуманитарно-экономический факультет

Бемарусь

\title{
Компьютерная этика и её восприятие белорусской студенческой момодежью на примере ГГТУ имени П.О. Сухого
}

Computer Ethics and its Perception by the Belarusian Student Youth on the Example of the Sukhoi State Technical University of Gomel

Etyka komputerowa i jej odbiór wśród białoruskiej młodzieży akademickiej. Przykład Homelskiego Państwowego Uniwersytetu Technicznego im. P.O. Suchowo

DOI: $10.34739 /$ doc.2021.18.05

\begin{abstract}
Аннотация: В статье рассматриваются специфика содержания понятия „компьютерная этика” и особенности восприятия данного явления современности студенческой молодежью. Особое внимание уделяется истории становления и основным положениям компьютерной этики. Анализируются результаты опроса студентов и магистрантов Гомельского государственного технического университета имени П.О. Сухого.

Кмючевые слова: информационная революция, информационные техномогии, профессиональная этика, информационная этика, компьютерная этика, киберэтика или виртуальная этика, студенческая молодежь

Abstract: This article discusses the specifics of "the computer ethics" content and the features of the student youth perception of this phenomenon. Special emphasis is placed on the history and provisions of computer ethics. The analyses refers to the results of the poll carried out among the students and master's degree students of Sukhoi State Technical University of Gomel.
\end{abstract}


Keywords: information revolution, information technology, professional ethics, information ethics computer ethics, virtual ethics or cyber ethics, student youth

Abstrakt: W artykule omówiono specyfikę treści pojęcia „etyka komputerowa” oraz cechy postrzegania tego zjawiska współczesności przez młodzież akademicką. Szczególną uwagę zwrócono na historię powstania i podstawowe założenia etyki komputerowej. Analizie poddano rezultaty badań w środowisku studentów i magistrantów Homelskiego Państwowego Uniwersytetu Technicznego im. P.O. Suchowo.

Słowa kluczowe: rewolucja informacyjna, technologie informacyjne, etyka zawodowa, etyka informacyjna, etyka komputerowa, etyka cybernetyczna oraz wirtualna, młodzież akademicka

\section{Введение}

Среди многочисленных характеристик френоменов современного общества, пожалуй, чаще всего встречается термин "информационный»: информационная революция, инфосфера, информационное общество, информационная безопасность, информационные войны, информационные технологии, философия информации и др. Гцобализационный дискурс дополняет картину такими явлениями и новыми терминами как информационный империализм, информа-ционный колониализм, информационная засоренность, информа-ционное неравенство. А актуальные свойства информационно-технологической парадигмы, такие как гибкость, сетевая могика и всепроницаемость коммуникации, требуют от мичности обладания такими качествами как, например, информационная грамотность, информационная активность и информационная толерантность. Результатом всех этих процессов и характеристик современности, безусловно, должно быть фрормирование соответствующего нормативно-ценностного мировоззрения, а точнее, новой этической подсистемы - этики информационной.

История становмения информационной этики связана с общим процессом активного формирования новых направлений в области прикладной и профессиональной этики, что стало ответом на быстрый рост современных технологий и усиление их влияния на общество. Наиболее активно последние десятиметия наряду с информационной этикой развиваются такие направления как биомедицинская и экологическая 
этики. Информационная этика связана с философией информации, а также с виртуамьной или киберэтикой.

Объектом данного исследования являются специфика содержания понятия "компьютерная этика", цемью же выступает анализ восприятия проблем и характеристик компьютерной этики студенческой молодежью. Дия реализации намеченного авторы стремятся прояснить специфику новых моральных положений и, опираясь на результаты опроса студентов и магистрантов технического университета, выявить степень актуальности и востребованности новых правим нравственности дмя Интернета.

\section{Компьютерная этика как}

\section{самостоятеиьная этическая дисципмина}

Информационная этика начинает свой путь во времена, когда Интернета еще не существовало. Начальным источником ее идей стало научное творчество американского профессора Массачусетского технологического института Норберта Винера (Norbert Wiener), который знаменит авторством нового направцения в науке - кибернетики. Работая вместе с комлегами над совершенствованием вооружений во время Второй мировой войны, Винер поразительно точно прогнозирует быстрое развитие электронных средств информации, компьютеров и то, что развитие цифровых технологий породит большое количество новых социально-этических вызовов ${ }^{1}$. Конечно, Винер не предполагал, что идеи, изцоженные им в работах Кибернетика, или управление и связь в животном и машине, Человеческое использование человеческих сушеств. Кибернетика и обиество, Твореи и робот приведут к формированию нового направления в этике. Он не явцяется и автором терминов "информационная этика" или "компьютерная этика", но именно его размышления сегодня являются фундаментом этих направлений в прикладной этике.

Винер отвергает этический релятивизм, предмагает универсальные принципы справедливости и фрормулирует методологию информационной этики и тем самым фактически

1 С.В. Силков, Винер Норберт, [в:] История философии. Энииклопедия, Минск 2002, c. $181-183$. 
формирует кросс-культурное основание будущей дисциплины. По его убеждению это домжна быть этика общечеловеческих ценностей, нацеленная на защиту, сохранение и продвижение, прежде всего таких феноменов как жизнь, здоровье, безопасность, счастье, свобода, знания, возможности ${ }^{2}$. Такой "гуманистический подход $\mathrm{k}$ формированию новой ветви прикладной этики оказался очень плодотворным. В дальнейшем особую роль в ее становлении и развитии сыграли У. Мейнер (Walter Maner), Д. Джонсон (Deborah Johnson), Дж. Мур (James Moor), Д. Готтербарн (Donald Gotterbarn), К. Гурняк-Косиковская (Krystyna Górniak-Kocikowska) и др.

Уолтер Мейнер первым подготовил начальный курс по информационной этике, однако отдавая его в печать, он решил назвать новое направление не информационной, а компьютерной этикой. Так как создание обеих этик имеет общую историю и цели, то часто эти термины рассматриваются как синонимы. Позднее, в начале XXI столетия, информационную этику стали рассматривать как область прикладной этики, которая изучает моральные аспекты производства информации, сбора информации и ее каталогизации, этические проблемы доступа к информации и распространения информации. Особое внимание уделяется вопросам прав и ответственности человека. Соответственно компьютерная этика - часть более широкого направления, это прикладная профессиональная этика, которая большей частью нацелена на исследование этических аспектов деятельности "компьютерных профессионалов" ${ }^{3}$.

Следующий важнейший этап в становлении компьютерной этики связан с американским журналом «Метафимософия" (Metaphilosophy), который в 1983 году объявиц конкурс на цучшее эссе о компьютерной этике, чтобы привлечь к ней внимание общественности. Победителем стал Дж. Мур и его эссе Что такое компьютерная этика? Работа была опубликована в специальном выпуске журнала "Компьютеры и этика»".

\footnotetext{
2 Ibidem.

${ }^{3}$ И.Ю. Алексеева, Е.Н. Шклярик, Что такое компьютерная этика?, „Вопросы фимософии" 2007, № 9, с. 63.

4 Ibidem.
} 
Два года спустя, бцагодаря гранту Ренсселаеровского политехнического института вышел учебник Деборы Джонсон Компьютерная этика. Фактически это был первый образовательный стандарт по новому дисциплинарному напра-влению. В нем рассматривались вопросы интемлектуальной собственности и собственности на программное обеспечение, проблемы конфиденциальности, обязанности "компьютерных профессионалов", проблема справедливого распределения технологий. Позднее Джонсон дополняет материалы своего образовательного модумя вопросами становцения этики Интернета 5 .

Однако далее, между наиболее известными специалистами в области профессиональной этики разворачивается серьезная дискуссия вокруг вопроса о предмете исследования компьютерной этики. Особенно активное участие в обмене мнениями принимают Д. Джонсон, Дж. Мур и Д. Готтенбарн. Следует заметить, что к этому времени (80-90-е годы XX века), благодаря многочисленным конференциям, новые дисциплины становятся популярными в США и обсуждение тематики исследования информационной и компьютерной этики становится регулярным. Накопленный опыт и теоретические исследования свидетельствовали о необходимости систематизации и структуризации предмета компьютерной этики и ее роли не только дмя "компьютерных профессионалов", ученых, но дмя системы образования в целом.

Так, Дж. Мур выдемяет ряд важнейших, с его точки зрения, особенностей компьютерной этики и видит в ней новую самостоятельную дисциплину. Он полагает, что компьютерные технологии характеризуются "цогической пластичностью", а компьютер становится универсальным инструментом, использование которого обеспечивает Аюдей новыми видами деятельности. Потенциальные возможности применения компьютерных технологий являются безграничными и эти "способности" компьютера в настоящее время во многом определяют пределы творчества и для самого человека. Чтобы решить задачу определения проблемного поля компьютерной

5 D.G. Johnson, Computer Ethics, London 1985. 
этики, по мнению Мура, следует испоцьзовать методологию консеквенциальной этики и деонтологииб.

Иная позиция у Д. Готтербарна, который рассматривает компьютерную этику как одну из разновидностей профессиональной этики, к примеру, этика юристов или врачей и полагает, что ее основная цель совершенствовать стандарты кодекса поведения профессионалов в области информационных технологий, с опорой на традиционные нравственные ценности и положения этики. На протяжении 1990-х годов он вместе с комлегами активно участвует в работе Ассоциации вычислитемьной техники (Association for Computer Machinery) и деятельности ряда учебных заведений, например, Института инженеров электроники и электротехники (Institute of Electrical and Electronic Engineers) над Кодексом профессионального поведения (Code of Ethics and Professional Conduct) ${ }^{7}$.

Современная мировая ситуация, которую Винер назвал "второй промышленной революцией", характеризуется еще и глобальностью всех процессов, поэтому нельзя не упомянуть идеи Кристины Гурняк-Косяковской. Она полагает, что парадигма господства и использования региональных этических систем изжила себя. Так, в Европе, например, традиционно использовались такие этические программы как утилитаризм или кантианская этика. Однако дмя века информации и глобализации необходима новая этическая модель - глобальная, а не региональная. По ее мнению, подходящий потенциал дмя формирования глобальной этики есть именно у информационной и компьютерной этики. Природа информационной революции указывает на подиинно всемирный масштаб развития

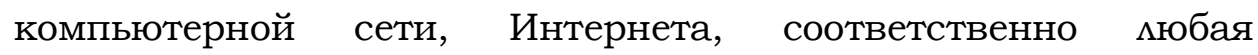
региональная этика, кроме глобальной информационной этики будет неэффективной. Следовательно, необходимы взаимно согласованные усимия и выработка совместных этических

6 J.H. Moor, What is computer ethics?, „Methaphilosophy” 1985, Vol. 16, No. 4, c. 266-275.

7 D. Gotterbarn, Computer ethics: Responsibility regained, „National Forum” 1991, No. 71 , c. 26-31. 
стандартов для продвижения и защиты общечеловеческих ценностей в подиинно глобамьном контексте 8 .

Информационная ревомюция, глобализация и Интернет, тем не менее, продомжают не только "сжимать" пространство и время, объединять мюдей, но и постоянно формировать новые феномены и проблемы. В области этики ответом на бурное развитие информационных, технологий и киберпространства стала киберэтика ими виртуальная этика. Киберэтика, согласно позиции российских исследователей А.Е. Войскунского и О.А. Дороховой, охватывает широкий круг проблем "сетевого общества": формирование моральных кодексов для пользователей социальных сетей и форумов, вне зависимости от их профессиональных интересов, вопросы авторского права (копирайта), плагиата, проблему равенства доступа к компьютерам и Интернету, недопущение преступного использования Сети террористами, киберпреступления, хакерство, шантаж, спам, фишинг, кибербумиинг и многое другое ${ }^{9}$.

Особенность проблемного поля киберэтики во многом связана и с особой “конструируемостью" иичности во “всемирной паутине». Современный Интернет дает мичности свободу идентификации: она может иметь виртуальное имя, виртуальный статус, виртуальные характеристики, виртуальные достоинства и недостатки. Она может идентифицировать себя с мюбой социальной группой и играть разные социальные роли. Виртуальная реальность в условиях интерактивности тоже становится проблемой киберэтики или виртуальной этики.

Компьютерная этика - очень динамичное направление, сочетающее теорию и практику. Проблемное поле данного этического направцения вкцючает: этическую ответственность за использование компьютера или информационных технологий в профессиональной деятельности, взаимодействии, общении с другими мюдьми, моральные проблемы доступа к информации и её распространения и т.д. Основной задачей компьютерной этики является формирование новых моральных норм поведения

\footnotetext{
8 Computer and Information Ethics, https://wwwplato.stanford.edu/entries/ethicscomputer/ (дата доступа: 30.06.2020).

9 А.Е. Войскунский, О.А. Дорохова, Становление киберэтики: исторические основания и современные проблемы, „Вопросы философии” 2010, № 5, с. 71.
} 
в условиях информатизации и компьютеризации не только на уровне общественных отношений, но и межличностных. Поэтому содержания понятий "компьютерная этика" и "информационная этика", по мнению авторов, максимально совпадают и явцяются синонимичными. Понятие "виртуальная этика" или "киберэтика" явцяется частью более широкого направцения, которое мы называем компьютерная этика.

\section{Пробцемы компьютерной этики}

\section{в восприятии студенческой молодежи}

Очевидно, что Интернет - важнейшая коммуникационная площадка дия молодого поколения. "Всемирная сеть" в настоящее время активно реализует и разнообразные образовательные проекты. Сопровождение процесса образования и воспитания подрастающего поколения - важнейшая цель ^юбой этики, все современные направления философии морали осуществцяют воспитательную функцию. Авторы статьи, будучи вузовскими преподавателями, нравственной составляющей образовательной деятельности придают особое значение, поэтому провели опрос среди студентов и магистрантов ГГТУ имени П.О. Сухого. Целью являлось выяснение их осведомленности относительно актуальных характеристик и проблем информационной культуры современного общества и особенностей компьютерной этики. Опрос бым проведен в 2019 и 2020 году, выборка составила 170 студентов и магистрантов технических и экономических специальностей. Среди респондентов 50\% составики студенты дневного и заочного отделения, и 50\% магистранты дневного и заочного отделения. Следует также отметить, что большинство участников опроса были жителями города (80\%), только 20\% явцялись жителями деревни или поселков городского типа. Значимость исследования обусловлена участием в опросе студентов и магистрантов специальности "Информационные технологии". Среди респондентов 25\% обучались на вышеназванной специальности.

Исследование показало, что большинство опрошенных знакомы с такими понятиями как "виртуальная" или "цифровая культура". Подавцяющее большинство $(78,2 \%)$ ответили утвердительно, 17,2\% сомневались, но обозначили ответ "наверное, да". 
Среди опрошенных только $1,1 \%$ обозначили, что не знакомы с данными понятиями, 3,5\% участников опроса не определимись с ответом.

Студентам было предложено перечислить явления электронной (виртуальной) культуры, которые представляют различные формы современной коммуникации. Ответы предлагалось студентам написать самим, но указать не более пяти ответов. Среди ответов студентов чаще всего быми: Интернет $(88,7 \%)$, социальные сети $(63,3 \%)$, сайты $(61,1 \%)$, электронные СМИ (46,9\%), электронная библиотека (Интернет версии учебников, научных журналов) (45,7\%). Наименее значимыми дмя респондентов и реже встречающиеся в ответах оказались такие явления, как виртуальные сообщества (13\%) и блоги $(11,9 \%)$. Результаты исследования показывают, что с понятием "виртуальная культура" студенты связывают понятие "Интернет", которое явцяется достаточно широким и охватывает все перечисленные студентами явления эмектронной кумьтуры. Поэтому задумываясь над проблемами компьютерной этики, студенты определяют прежде всего принципы пользования Интернетом.

Студентам было предложено выбрать наиболее значимые для них характеристики электронной культуры, которые, согласно разцичным исследованиям в сфере социогуманитарных наук, можно соотнести с современной электронной кумьтурой ${ }^{10}$. Чаще всего респонденты выбирали такие, как свобода доступа $(65,5 \%)$, дистанционность $(53,6 \%)$, сосуществование различных потоков информации, стилей, жанров (36,8\%), инновационность, существование через внедрение и постоянное обновление научных разработок (особенно в искусстве и электронной коммуникации) (35\%), развлекательный, игровой, рекреационный характер (32,2\%), открытость для членов информационного общества (тех, кто обладает электронными ресурсами) (32,2\%) (рис. 1). Наименее значимыми характеристиками среди предложенньх для респондентов оказались миберальность (15\%) и доминирование визуального над смысловым (14\%) (рис. 1). Результаты анализа показывают, что в восприятии студен-

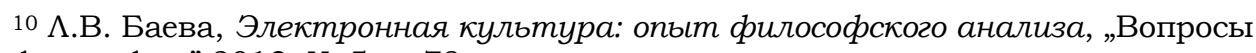
фимософии" 2013, № 5, с. 78 . 
ческой молодежи электронная культура, а именно Интернет явцяется, прежде всего, возможностью свободного доступа к разАичным источникам информации.

Рисунок 1. Распределение ответов респондентов на вопрос:

Какие характеристики, по Вашему мнению, можно соотнести с электронной (виртуальной) культурой? (Возможно несколько вариантов ответов, но не более 5 позиций)

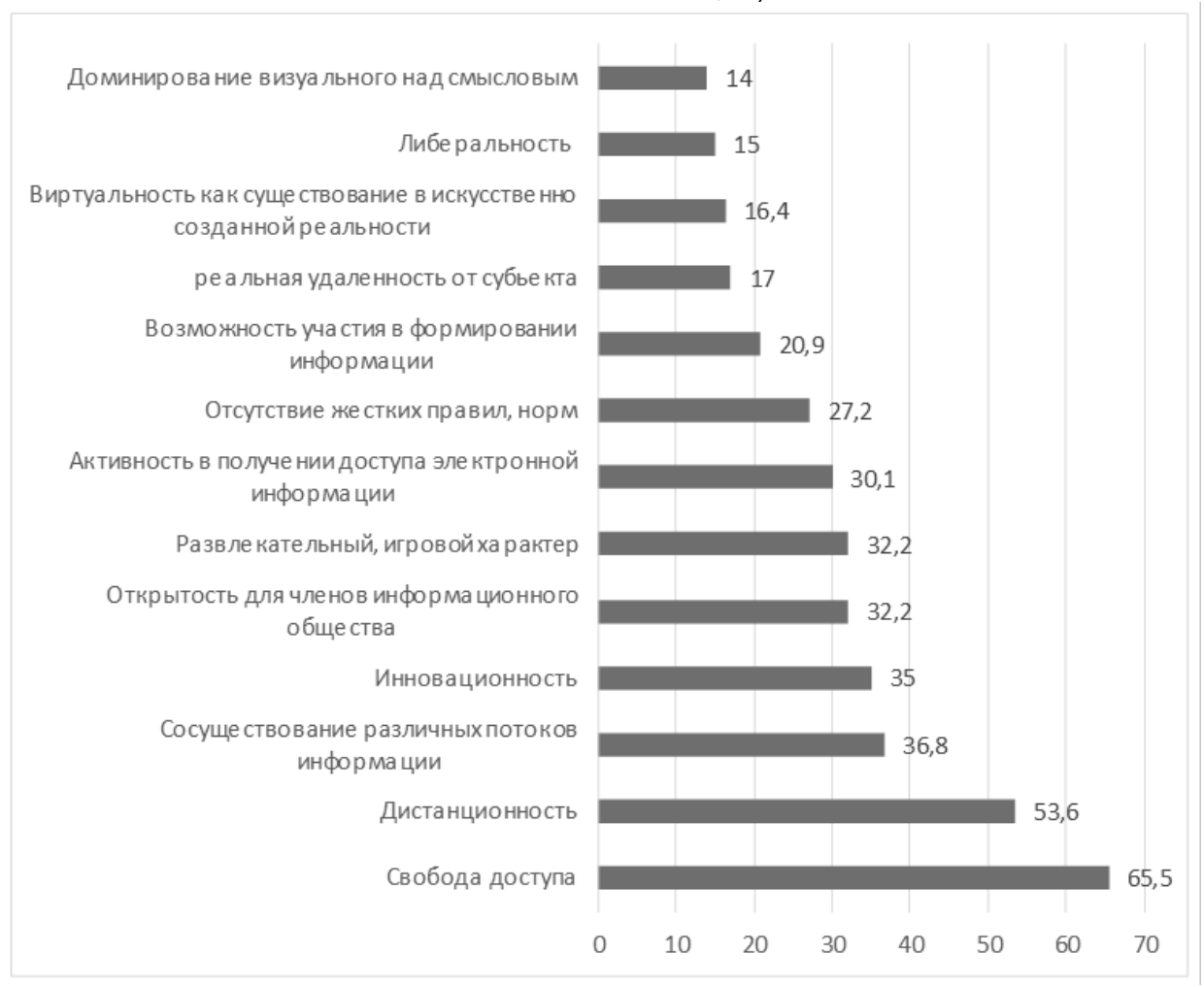

В связи с ростом популярности Интернета и его возможностей, вопрос о необходимости выработки общих стандартов поведения и формирования компьютерной или виртуальной этики является очень актуальным. Среди респондентов третья часть $(35,6 \%)$ ответили утвердительно, что необходимо разработать систему этических норм, 28,2\% указали - "наверное, да" это необходимо. Примечательным является факт, что практически четверть $(24,3 \%)$ среди опрошенных представителей студенческой молодежи считает, что нет необходимости разработки общих стандартов поведения для пользования Интернетом. 
11,9\% опрошенных не определились со своей позицией относительно разработки этических норм.

Существуют разные варианты формулировок основных принципов виртуальной этики. Авторы статьи предложили магистрантам университета выбрать наиболее важные дмя них позиции, но не более пяти в каждом из предложенных вариантов для киберпространства "правим" этики: И.А. Кумыцгановой (МГУ имени М. Аомоносова) ${ }^{11}$ и В. Ши (Virginia Shea) ${ }^{12}$. Принципы виртуальной этики, представменные российской ученой, кандидатом филологических наук И.А. Кумылгановой, более ориентированы на составление основных правил использования компьютера, программного обеспечением и информации в Интернет пространстве. Принципы, составленные американской исследовательницей Вирджинией Ши сконцентрированы в большей степени на правимах межличностного общения в Интернете.

В первом варианте предложенных принципов виртуальной этики позиции распределились следующим образом: большинство респондентов указали на принципы не использовать компьютер с целью навредить цюдям $(63,1 \%)$, дия воровства $(60,8 \%)$, для распространения можной информации (55,7\%) (рис. 2). Менее значимыми дмя студенческой молодежи оказались принципы, сформулированные как: не присваивать интелмектуальную собственность $(42,1 \%)$, а также не создавать помех и не вмешиваться в работу других пользователей компьютерных сетей $(38,6 \%)$ (рис. 2).

Наименее важными для участников опроса оказались принципы не использовать ворованное программное обеспечение $(13,6 \%)$ и не использовать компьютерное оборудование или сетевые ресурсы без разрешения или соответствующей компенсации $(9,1 \%)$.

\footnotetext{
11 И.А. Кумымганова, Интернет и этика, [в:] К мобильному обшеству: утопии и реальность, (ред.) Я.Н. Засурский, Москва 2009, с. 81- 85.

12 V. Shea, The Core Rules of Netiquette, https://coursedesign.colostate.edu/ obj/corerulesnet.html (дата доступа: 4.12.2020).
} 
Рисунок 2. Распределение ответов респондентов при ответе на вопрос:

Какие из указанных принципов виртуальной этики, предложенные И.А. Кумыцгановой, значимы дмя Вас? (Возможно несколько вариантов ответов, но не более 5 позиций)

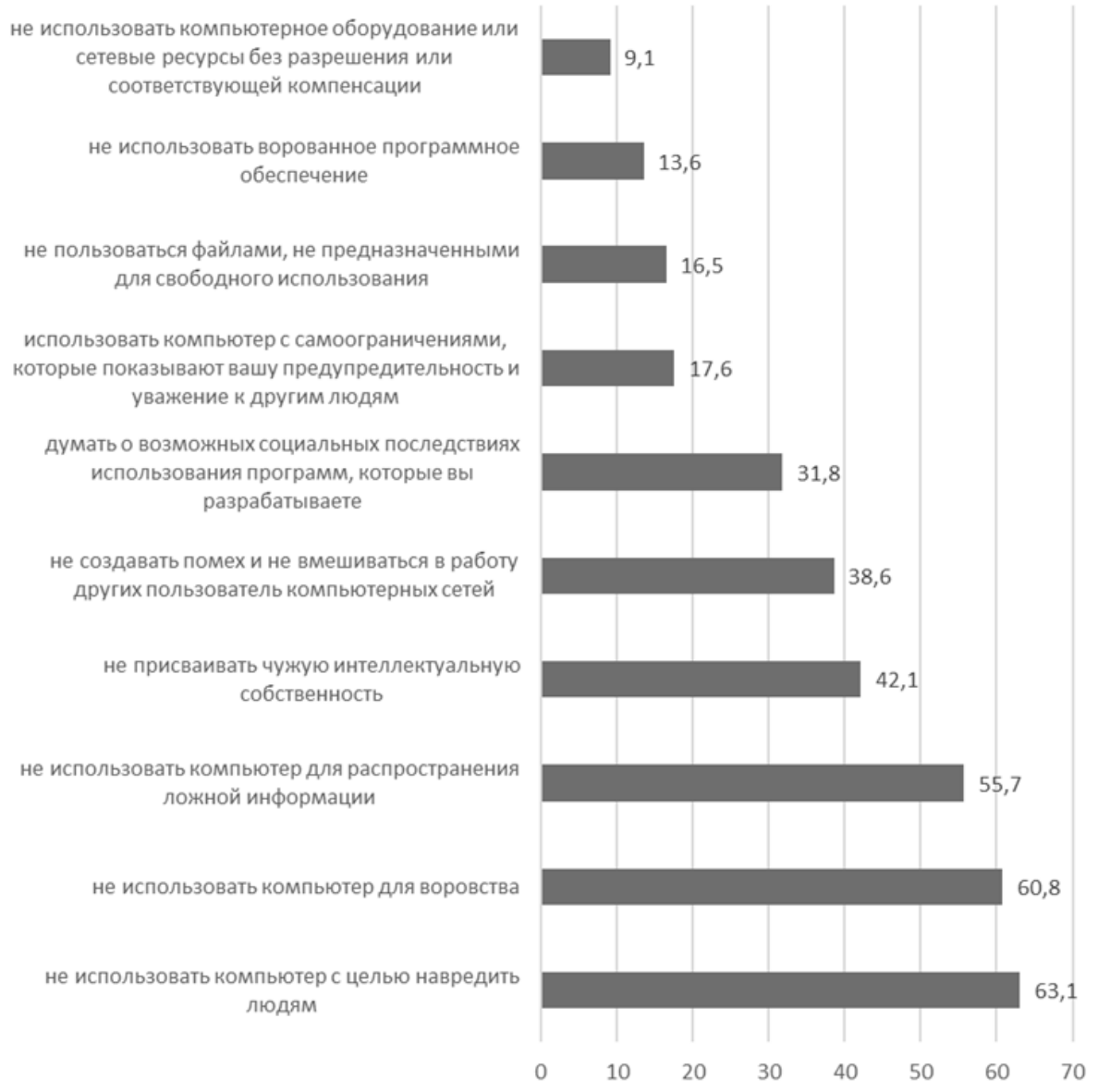

Проанализировав результаты данной таблицы, можно сделать заключение, что участники опроса воспринимают Интернет прежде всего как виртуальное пространство, где есть свободный доступ $\mathrm{x}$ бесплатной информации. Смысловое содержание выражения "не исполь-зовать компьютер дмя воровства" явно не соотносится дия подавцяющего большинства со значением суждений "не использовать ворованное программное обеспечение» и «не использовать компьютерное оборудование или сетевые ресурсы без разрешения или соответствующей компенсации". Поцучается, что воровать с 
помощью компьютера в Интернет-пространстве это пиохо, но поцьзоваться ворованными или полученными без разрешения программами, файлами вполне допустимо. Ответы студентов указывают на размытость, нечеткость понимания ответственности за использование компьютера и информационных технологий в профессио-нальной деятемьности и межличностном общении.

Рисунок 3. Распределение ответов респондентов при ответе на вопрос: Какие из указанных принципов виртуальной этики, предложенные В. Ши, значимы для Вас? (Возможно несколько вариантов ответов, но не более 5 позиций)

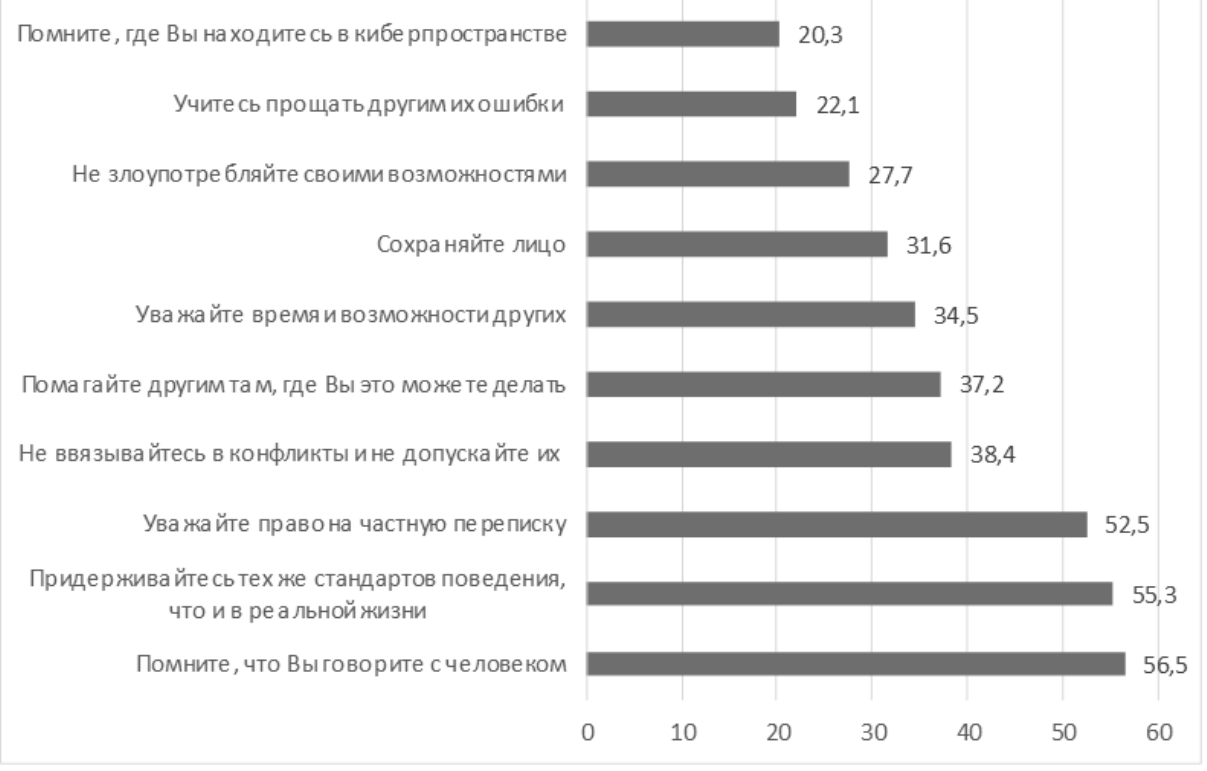

Следует отметить, что студенты охотнее воспользовались правом обозначить пять позиций в предложенном варианте принципов виртуальной этики американской исследовательницы Вирджинией Ши. Подавцяющее бомьшинство (90\%) обозначими 5 позиций. Среди правиц "Нетикета" наиболее популярными оказались следующие: "помните, что Вы говорите с человеком" (56,5\%), "придерживайтесь тех же стандартов поведения, что и в реальной жизни" $(55,3 \%)$, "уважайте право на частную переписку" (52,5\%) (рис. 3). Наименее значимыми среди правил виртуальной этики предложенных во втором варианте оказались: "учитесь прощать другим их ошибки" (22,1\%), 
"помните, где Вы находитесь в киберпространстве" (20,3\%) (рис. 3). Согласно выбору респондентов, правила, которые обязывают при непосредственном межличностном общении оказались наиболее понятными и значимыми. Студенты не разделяют этические принципы межличностного общения в виртуальной среде и в реальной жизни, дмя них они одинаковы.

\section{Закиючение}

Таким образом, эпоха информационной революции активно формирует новую информационную или цифровую культуру и соответственно новые направления этических учений. Компьютерная этика, являясь разновидностью прикладной и профессиональной этики, не отрицает традиционные нравственные ценности, но дополняет их новым содержанием, исходя из требований современного общества.

В условиях постиндустриального общества понятия и явцения, связанные с электронной (виртуальной) культурой не являются чуждыми, они становиться частью повседневной жизни современной белорусской студенческой молодежи. Дия большинства студентов и магистрантов ГГТУ имени П.О. Сухого понятие "электронная культура" синонимично понятию "Интернет", в меньшей степени это понятие связывают с понятиями "виртуальные сообщества" и "блоги". Большая половина участников проведенного опроса согласны с суждением о необходимости выработки этических правил для пользования Интернетом, но при этом четверть придерживаются позиции, что такой необходимости нет. Наиболее значимыми характеристиками электронной культуры дмя респондентов оказались свобода доступа к различным видам информации и удаленность.

При выборе этических принципов виртуального пространства участники опроса чаще выбирали принципы, связанные с межличностным общением. Принципы компьютерной этики, указывающие на правила межличностного общения, оказались дия студентов более понятными. Студенты не раздемяют этические принципы межличностного общения в виртуальной среде и в реальной жизни, дмя них они одинаковы. Настораживает в ответах студентов отсутствие осознания ответствен- 
ности за использование компьютера или информационных технологий в профессиональной деятельности и межличностном общении.

Этические проблемы Интернет пространства интересны и необходимы дия осмысления современным молодым что показали резумьтаты опроса студентов и магистрантов ГГТУ имени П.О. Сухого. Значимость данной проблематики и наметившиеся прорехи в понимании ответственности при использовании компьютера и информационных технологий свидетельствует о целесообразности ее исследования и, возможно, разработки соответствующих учебных (специализированных) модулей с целью внедрения их в учебный процесс.

\section{Бибмиография / References}

Alekseeva I.Û., Šklârik E.N., Čto takoe komp'ûternaâ ètika?, „Voprosy filosofii” 2007, № 9. [А^ексеева И.Ю., Шклярик Е.Н., Что такое компьютерная этика?, „Вопросы фимософии” 2007, № 9].

Baeva L.V., Èlektronnaâ kul'tura: opyt filosofskogo analiza, „Voprosy filosofii” 2013, № 5. [Баева М.В., Электронная культура: опьт философского анализа, „Вопросы философии” 2013, № 5].

Computer and Information Ethics, https://wwwplato.stanford.edu/entries / ethics-computer/ (дата доступа: 30.06.2020).

Gotterbarn D., Computer ethics: Responsibility regained, „National Forum” 1991, No. 71 .

Johnson D.G., Computer Ethics, London 1985.

Kumylganova I.A., Internet i ètika, [v:] $K$ mobil'nomu obŝestvu: utopii $i$ real'nost' (red.), Â.N. Zasurskij, Moskva 2009. [Кумымганова И.А., Интернет и этика, [в:] $K$ мобильному обиеству: утопии и реальность, (ред.) Я.Н. Засурский, Москва 2009].

Moor J.H., What is computer ethics?, „Methaphilosophy” 1985, Vol. 16, No. 4.

Shea V., The Core Rules of Netiquette, https:/ / coursedesign.colostate.edu/ obj/corerulesnet.html (дата доступа: 4.12.2020).

Silkov S.V., Viner Norbert, [v:] Istoriâ filosofii. Ènciklopediâ, Minsk 2002. [Сикков С.В., Винер Норберт, [в:] История философии. Энииклопедия, Минск 2002].

Vojskunskij A.E., Dorohova O.A., Stanovlenie kiberètiki: istoričeskie osnovaniâ $i$ souremennye problemy, „Voprosy filosofii” 2010, № 5. [Войскунский А.Е., Дорохова О.А., Становление киберэтики: исторические основания и современные проблемы, „Вопросы фимософии”, 2010, № 5]. 
